\title{
Cenário da educação superior à distância em saúde no Brasil: a situação da Enfermagema
}

\author{
Scenario of distance higher education in health in Brazil: the situation of Nursing \\ Escenario de la educación superior a distancia en salud en Brasil: situación de la Enfermería
}

\author{
Fabiana Alves Soares ${ }^{1}$ (C) \\ Karla Kelma Almeida Rocha ${ }^{1}$ (D) \\ Raquel de Aguiar Portela ${ }^{1}$ (1) \\ Andréa Cristina Oliveira Silva ${ }^{1}$ (1) \\ Rita da Graça Carvalhal Frazão Corrêa ${ }^{1}$ (D) \\ Bruno Luciano Carneiro Alves de Oliveira ${ }^{1}$ (D)
}

1. Universidade Federal do Maranhão. São Luís, MA. Brasil
Autor Correspondente Fabiana Alves Soares

E-mail: fabianaalvessoares23@hotmail.com.

Recebido em 07/05/2020.

Aprovado em 03/12/2020.

DOl:https://doi.org/10.1590/2177-9465-EAN-2020-0145

\begin{abstract}
Resumo
Objetivo: Analisar a oferta dos cursos de graduação em saúde na modalidade de Ensino a Distância no Brasil, destacando suas principais características para Enfermagem. Método: Estudo transversal baseado em dados on line de cursos de graduação em saúde a distância, criados entre 2005 e 2020. Para doze graduações em saúde, destacaram-se características da criação e distribuição do ensino a distância, enfatizando-se a situação da Enfermagem. Realizaram-se testes de significância estatística ( $(\mathrm{a}=5 \%)$ e mapa. Resultados: Verificaram-se 431 cursos de graduação em saúde, sendo a maioria deles criados entre 2017 e 2020 ( $\geq 61,4 \%$ ). Para Enfermagem, o periodo de maior criação foi anterior (entre 2013 e 2016; 72,7\%) ( $p=0,001$ ). Todos os cursos eram vinculados a instituições privadas, que ofertavam 82.000 vagas, distribuídas em 1.363 Polos por todos os estados. Verificou-se predomínio em São Paulo (23,9\%) e nas cidades localizadas no interior dos estados (64,3\%) $(p=0,001)$. Conclusão e implicações para prática: Houve aumento significativo de cursos de graduação em saúde no ensino a distância no Brasil. Para Enfermagem, estes se caracterizaram por oferta privada e localizada no interior dos estados. Contudo, a distribuição regional ainda é desigual, concentrando Polos nas regiões mais ricas e centrais do país, e longe das áreas com maiores necessidades de saúde.
\end{abstract} Palavras-chave: Saúde; Enfermagem; Educação em Enfermagem; Educação Superior; Ensino a Distância.

\begin{abstract}
Objective: To analyze the offer of undergraduate health courses in the Distance Learning modality in Brazil, highlighting its main characteristics for Nursing. Method: This is a cross-sectional study based on distance health undergraduate courses online data, created between 2005 and 2020. For twelve health degrees, characteristics of the creation and distribution of distance learning were highlighted, emphasizing Nursing courses. Statistical significance tests $(a=5 \%)$ and mapping were performed. Results: There were 43 undergraduate courses in health, most of which were created between 2017 and $2020(\geq 61.4 \%)$. For Nursing most courses were created in earlier years (2013 and 2016; 72.7\%) $(p=0.001)$. The courses were linked to private institutions, which offered 82,000 seats and are distributed in 1,363 hubs across all states. Courses predominated in São Paulo (23.9\%) and non-capital cities $(64.3 \%)(p=0.001)$. Conclusion and implications for the practice: There has been a significant increase in distance education in Brazil's undergraduate health courses. For Nursing, the courses were characterized by private offers located in non-capital cities. However, the regional distribution is still uneven, concentrating hubs in the country's richest and most central regions and away from areas with the greatest health needs.
\end{abstract}

Keywords: Health; Nursing; Nursing Education; College education; Distance learning.

\section{Resumen}

Objetivo: Analizar la oferta de estudios superiores en salud bajo la modalidad de Educación a Distancia en Brasil, destacando sus principales características para Enfermería. Método: Estudio transversal a partir de datos en línea de las carreras de grado en salud a distancia, creadas entre 2005 y 2020. Para doce titulaciones de salud se destacaron características de la creación y distribución de la educación a distancia, destacando la situación de Enfermería. Se realizaron pruebas de significación estadística ( $a=5 \%$ y mapa. Resultados: Se detectaron 431 carreras de grado en salud, la mayoría de las cuales se crearon entre 2017 y 2020 ( $\geq 61,4 \%)$. Para Enfermería, el período de mayor creación fue anterior (entre 2013 y $2016 ; 72,7 \%)(p=0,001)$. Todos los cursos estuvieron vinculados a instituciones privadas, que ofrecieron 82.000 plazas, distribuidas en 1.363 centros en todos los estados. Se registró predominio de cursos en São Paulo (23,9\%) y en ciudades del interior de los estados $(64,3 \%)(p=0,001)$. Conclusión e implicaciones para la práctica: Se advierte un aumento significativo en los cursos de pregrado en salud en educación a distancia en Brasil. Para Enfermería, estos se caracterizaron por una oferta privada ubicada en el interior de los estados. Sin embargo, la distribución regional sigue siendo desigual, concentrada en las regiones más ricas y céntricas del país, y lejos de las áreas con mayores necesidades de salud.

Palabras clave: Salud, Enfermería; Educación en enfermería; Educación universitaria; Ensine a distancia. 


\section{INTRODUÇÃO}

O número de Instituições de Ensino Superior (IES) no Brasil vem crescendo progressivamente desde o final da década de 1970. O incremento foi influenciado pela rápida propagação de tecnologias educacionais, induções de políticas públicas e desenvolvimento econômico e social do país. ${ }^{1}$ Estes fatores favoreceram a ampliação da oferta de cursos superiores nas mais diversas áreas e modalidades, sobretudo no formato de Ensino a Distância (EaD) no país. ${ }^{1-3}$

A modalidade EaD demanda um conjunto específico de elementos didático-pedagógicos e organização curricular prévia. Alunos e professores (tutores) utilizam sistema de gestão de aprendizagem baseado em plataformas digitais virtuais e o processo de aprendizagem ocorre sem que os envolvidos estejam fisicamente presentes. Sendo por vezes erroneamente tratada como sinônimo de "ensino remoto", que mesmo utilizando a internet como principal ferramenta mediadora do ensinoaprendizado, difere da EaD por ser uma solução temporária com o intuito de proporcionar a continuidade das atividades pedagógicas quando o ensino presencial se torna inviável devido a situações particulares. ${ }^{4}$

No Brasil, a difusão e desenvolvimento da EaD tem pouco mais de 20 anos, sendo oficialmente reconhecida por atos regulatórios legais. ${ }^{5,6}$ Dados do censo da educação superior apontam rápida expansão do Ensino a Distância no país como modalidade de ensino superior, triplicando o número de ingressantes em seus cursos no período de 2017 a $2018 .^{7}$

Essa modalidade também vem se destacando na saúde, sendo implementada com o argumento de capacitar e oportunizar conhecimentos para moradores de localidades remotas do país. ${ }^{8}$ Dados do Ministério da Educação revelam que entre 2005 e 2020, apenas para as graduações de Biomedicina, Educação Física, Enfermagem, Farmácia, Fisioterapia, Fonoaudiologia, Nutrição, Serviço Social e Terapia Ocupacional, foram implantados 501 cursos na modalidade EaD (licenciatura e bacharelado) ofertando pouco mais de meio milhão de vagas. ${ }^{9}$

Nesse cenário, o mercado de ensino superior na modalidade EaD tem incorporado a Educação em Enfermagem com oferta crescente e significativa do número de vagas em todo país. ${ }^{10}$ Trabalho prévio indica que até 2015 já existiam 75.660 vagas para Enfermagem nessa modalidade, com número relativamente pequeno de 475 concluintes entre 2010 e $2015^{10}$ e outros 288 entre 2016 e 2018. ${ }^{7}$ Porém, independente do quantitativo, especialistas da área de Educação em Enfermagem e o Conselho Federal de Enfermagem (Cofen) alertam sobre a necessidade do debate em relação a esse tipo de ensino.

Destacam ainda, contradições dessa modalidade de Ensino, as quais são pontos mais vulneráveis na formação EaD. ${ }^{10,11}$ Entre elas, a incapacidade de garantir formação com base teórica sólida; incapacidade de qualificar profissionais dentro das prerrogativas de competências definidas nas Diretrizes Curriculares Nacionais (DCNs) dos cursos de graduação em Enfermagem; inserção tardia e fragmentada nos serviços de saúde com formação pouco embasada em experiências decorrentes de práticas clínicas, contato com usuários e outros profissionais dos sistemas de saúde. Apesar disso, nos últimos anos o Ministério da Educação permanece autorizando e reconhecendo a criação e o funcionamento de cursos de graduação em Enfermagem na modalidade EaD. ${ }^{10,11}$

Contudo, a distribuição regional dos seus Polos de ensino ocorre em sobreposição à oferta para os cursos presenciais, mantendo a concentração de grande parte dos Polos nas regiões mais desenvolvidas do país. Por outro lado, ainda são escassos estudos que analisem as características dessa expansão. Essa condição limita reflexões que auxiliem na condução de ações de enfrentamento dos problemas associados ao modelo de EaD em saúde no Brasil, especialmente no caso da Enfermagem, pois essa rápida expansão da oferta EaD pode implicar em resposta negativa para a profissão, sistema de saúde e para toda sociedade. ${ }^{12}$

Portanto, este estudo analisou a oferta dos cursos de graduação em saúde na modalidade de Ensino a Distância no Brasil, destacando suas principais características para Enfermagem.

\section{MÉTODO}

Trata-se de estudo transversal baseado na análise de dados secundários disponíveis on line no sistema eletrônico do Ministério da Educação do Brasil (Cadastro e-MEC). Este sistema reúne a base de dados oficial e administrativa de informações relativas as IES e cursos de graduação de todas as áreas, registrados no Sistema Federal de Controle do Ensino de Graduação. ${ }^{9}$ A coleta de dados foi realizada na aba de Consulta Avançada do sistema e-MEC. Inicialmente, foram incluídas na pesquisa as IES que ofertavam cursos de graduação em saúde na modalidade EaD desde 2005 até fevereiro de 2020, data da coleta dos dados. Não foram incluídos os cursos de graduação com data de criação anterior a 2005, pois foi somente neste ano, que passou a ser oficialmente regulamentada a modalidade de ensino EaD no Brasil. ${ }^{5,6}$

Foram consideradas as seguintes graduações em saúde: Biomedicina, Educação Física, Enfermagem, Farmácia, Fisioterapia, Fonoaudiologia, Nutrição, Serviço Social, Terapia Ocupacional, Odontologia, Psicologia e Medicina. Para estes cursos, foram descritos o número de cursos ofertados e o ano do ato de criação deles. Nesta análise, não foram incluídos os cursos para as áreas de Biologia e Medicina Veterinária, por serem profissões que não atuam diretamente no cuidado em saúde de seres humanos.

Em seguida, buscou-se destacar as principais características da EaD para Enfermagem. Para tanto, foram consideradas as variáveis: número de cursos, vagas ofertadas, ano do ato de criação, situação do curso (em atividade, em extinção ou extinto), tipo de cidade sede do Polo (Capital, Interior do estado e Área metropolitana, excluído capital), Unidade Federativa (UF), região do país (Nordeste, Norte, Centro-oeste, Sudeste e Sul).

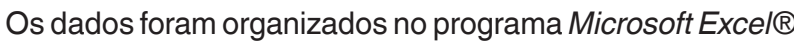
e em seguida transferidos para o software Stata ${ }^{\circledR}$, versão 14.0. Realizaram-se testes de Qui-quadrado de Pearson para se verificar diferenças estatisticamente significantes entre o 
número dos cursos de graduação $\mathrm{EaD}$ em saúde ofertados e o ano do ato de criação deles, e o tipo de cidade sede do Polo do curso de graduação em Enfermagem e as regiões do Brasil. As diferenças foram assim consideradas quando $p$-valor $<0,05$. Os resultados foram apresentados através de tabelas e mapa espacial realizado por meio do Q-gis 3.12.0®, este descreveu a distribuição geográfica dos Polos EaD para Enfermagem.

A pesquisa foi elaborada com agregados de dados secundários disponíveis on-line, os quais não contêm informações sigilosas que permitam a identificação dos sujeitos. Assim, foi dispensada a apreciação por Comitê de Ética em pesquisa envolvendo seres humanos. Porém, foram respeitadas as questões éticas, diretrizes e normas que regulamentam a pesquisa no Brasil.

\section{RESULTADOS}

Entre 2005 e fevereiro de 2020 foram criados 431 cursos de graduação em saúde na modalidade EaD no Brasil. Para os doze cursos de graduações analisados, observou-se importante crescimento no número desses cursos e vagas (em licenciatura e bacharelado) ao longo desses anos, com diferenças estatisticamente significante entre eles $(p=0,001)$.

Para Enfermagem, o primeiro curso na modalidade EaD foi criado em 2005 e o último em 2016, totalizando onze cursos. O seu período de maior incremento foi entre 2013 e 2016 (72,7\%). Já para os demais cursos de graduação, esse incremento ocorreu no período posterior entre 2017 e 2020 (69,5\%). Cursos de Biomedicina, Farmácia, Fisioterapia, Fonoaudiologia, Nutrição e Terapia Ocupacional só foram criados de 2013 em diante. Não constou na base de dados do e-MEC nenhum curso de graduação em Odontologia, Psicologia e Medicina na modalidade de EaD no período analisado (Tabela 1).

Para a Enfermagem, foram verificados onze cursos de graduação em EaD, sendo que nove encontravam-se em atividade. Todos vinculados a IES privadas e ofereciam 82.000 vagas. Apenas um curso na modalidade $\mathrm{EaD}$ era vinculado à rede pública e disponibilizava curso de licenciatura que ofertava 240 vagas, porém já foi extinto (Tabela 2).

Tabela 1. Ano de criação dos cursos de graduação na área da Saúde na modalidade EaD no Brasil, 2005 a 2020.

\begin{tabular}{|c|c|c|c|c|c|c|c|c|c|c|c|}
\hline \multicolumn{12}{|c|}{ Ano de criação do curso } \\
\hline \multirow{2}{*}{ Curso de graduação } & \multicolumn{2}{|c|}{2005 a 2008} & \multicolumn{2}{|c|}{2009 a 2012} & \multicolumn{2}{|c|}{2013 a 2016} & \multicolumn{2}{|c|}{2017 a 2020} & \multicolumn{2}{|c|}{ Total } & \multirow{2}{*}{$p$-valor ${ }^{1}$} \\
\hline & $\mathrm{N}$ & $\%$ & $\mathrm{~N}$ & $\%$ & $\mathrm{~N}$ & $\%$ & $\mathrm{~N}$ & $\%$ & $\mathrm{~N}$ & $\%$ & \\
\hline Biomedicina & 0 & 0,0 & 0 & 0,0 & 4 & 9,1 & 40 & 90,9 & 44 & 100,0 & \\
\hline Educação Física & 8 & 5,5 & 8 & 5,5 & 29 & 19,9 & 101 & 69,2 & 146 & 100,0 & 0,001 \\
\hline Enfermagem & 3 & 27,3 & 0 & 0,0 & 8 & 72,7 & 0 & 0,0 & 11 & 100,0 & \\
\hline Farmácia & 0 & 0,0 & 0 & 0,0 & 11 & 25,6 & 32 & 74,4 & 43 & 100,0 & \\
\hline Fisioterapia & 1 & 2,3 & 0 & 0,0 & 11 & 25,0 & 32 & 72,7 & 44 & 100,0 & \\
\hline Fonoaudiologia & 0 & 0,0 & 0 & 0,0 & 1 & 25,0 & 3 & 75,0 & 4 & 100,0 & \\
\hline Nutrição & 0 & 0,0 & 0 & 0,0 & 12 & 25,0 & 36 & 75,0 & 48 & 100,0 & \\
\hline Serviço Social & 17 & 16,8 & 10 & 9,9 & 12 & 11,9 & 62 & 61,4 & 91 & 100,0 & \\
\hline Terapia Ocupacional & 0 & 0,0 & 0 & 0,0 & 1 & 20,0 & 4 & 80,0 & 5 & 100,0 & \\
\hline Total & 29 & 6,5 & 18 & 4,0 & 89 & 20,0 & 310 & 69,5 & 431 & 100,0 & \\
\hline
\end{tabular}

Fonte: Portal e-MEC, 2020.9

Notas: 1- Teste de Qui-quadrado de Person.

Tabela 2. Caracterização e oferta de vagas dos cursos de graduação em Enfermagem na modalidade EaD segundo Administração e Grau de graduação no Brasil, 2005-2020.

\begin{tabular}{|c|c|c|c|c|c|c|c|c|}
\hline \multicolumn{9}{|c|}{ Atividade } \\
\hline \multirow{2}{*}{ Caracterização } & \multicolumn{2}{|c|}{ Ativo } & \multicolumn{2}{|c|}{ Em Extinção } & \multicolumn{2}{|c|}{ Extintas } & \multicolumn{2}{|c|}{ Total } \\
\hline & Cursos & Vagas & Cursos & Vagas & Cursos & Vagas & Cursos & Vagas \\
\hline \multicolumn{9}{|l|}{ Administração } \\
\hline Pública & & & & & 1 & 240 & 1 & 240 \\
\hline Privada & 9 & 82.000 & 1 & 240 & & & 10 & 82.240 \\
\hline \multicolumn{9}{|l|}{ Grau } \\
\hline Licenciatura & & & & & 1 & 240 & 1 & 240 \\
\hline Bacharelado & 9 & 82.000 & 1 & 240 & & & 10 & 82.240 \\
\hline Total & 9 & 82.000 & 1 & 240 & 1 & 240 & 11 & 82.480 \\
\hline
\end{tabular}

Fonte: Portal e-MEC, $2020 .^{9}$ 
No Brasil, verificou-se que havia 1.363 Polos desses cursos ativos de graduação em Enfermagem EaD, distribuídos em todos os 26 estados e Distrito Federal. O estado de São Paulo destacou-se por concentrar 23,9\% dos Polos, seguido do estado de Minas Gerais com 9,2\% e Bahia com 6,7\%. Considerando-se as macrorregiões do Brasil, o quantitativo de Polos na região Sudeste foi o maior do país com $37,7 \%$, seguido da região Nordeste com $25,9 \%$. As regiões Norte $(13,3 \%)$, Sul $(11,9 \%)$ e Centro-oeste $(11,2 \%)$ apresentaram as menores proporções (Figura 1).
Observou-se diferença estatisticamente significante ( $p$-valor=0,001) na distribuição da localização dos Polos de curso de graduação Enfermagem na modalidade $\mathrm{EaD}$ segundo o tipo de cidade e região do país. Resultados indicaram que $64,3 \%$ dos Polos estavam implantados em cidades localizadas no interior dos estados, variando de $49,2 \%$ no Sul a $70,0 \%$ no Norte. Porém, destacou-se ainda a concentração de Polos nas capitais da região Centro-oeste $(28,1 \%)$ e nas áreas metropolitanas da região Sul $(42,5 \%)$ (Tabela 3$)$.

\begin{tabular}{lcc}
\hline Região & $\mathbf{N}(\%)$ & Contagem UF \\
\hline Sudeste & $514(37,7 \%)$ & 4 \\
Nordeste & $353(25,9 \%)$ & 9 \\
Norte & $181(13,3 \%)$ & 7 \\
$\begin{array}{l}\text { Sul } \\
\text { Centro- } \\
\text { oeste }\end{array}$ & $162(11,9 \%)$ & 3 \\
\hline Total & $153(11,2 \%)$ & 4 \\
\hline
\end{tabular}

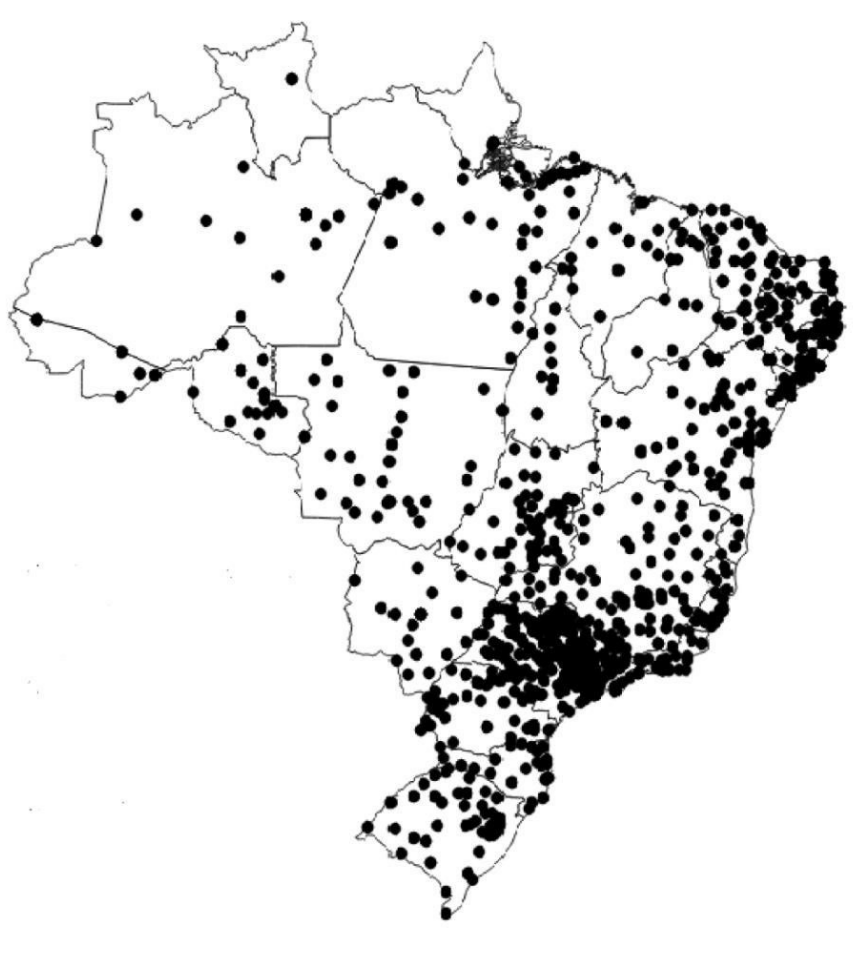

\begin{tabular}{lc}
\hline \multicolumn{1}{c}{ Unidade } & N (\%) \\
Federada UF & $24(1,8 \%)$ \\
\hline ES & $126(9,2 \%)$ \\
MG & $326(23,9 \%)$ \\
SP & $38(2,8 \%)$ \\
RJ & $25(1,8 \%)$ \\
AL & $91(6,7 \%)$ \\
BA & $52(3,8 \%)$ \\
CE & $23(1,7 \%)$ \\
MA & $29(2,1 \%)$ \\
PB & $65(4,8 \%)$ \\
PE & $19(1,4 \%)$ \\
PI & $33(2,4 \%)$ \\
RN & $16(1,2 \%)$ \\
SE & $13(0,9 \%)$ \\
AC & $21(1,5 \%)$ \\
AM & $7(0,5 \%)$ \\
AP & $88(6,5 \%)$ \\
PA & $29(2,1 \%)$ \\
RO & $3(0,2 \%)$ \\
RR & $20(1,5 \%)$ \\
TO & $61(4,5 \%)$ \\
PR & $36(2,6 \%)$ \\
SC & $65(4,8 \%)$ \\
RS & $24(1,8 \%)$ \\
DF & $61(4,5 \%)$ \\
GO & $30(2,2 \%)$ \\
MS & $38(2,8 \%)$ \\
MT & $1.363(100,0 \%)$ \\
\hline Total: 27 & \\
\hline & \\
\hline & \\
\hline
\end{tabular}

Figura 1. Distribuição geográfica dos Polos de cursos de graduação em Enfermagem EaD no Brasil, 2020. Fonte: Portal e-MEC, 2020. ${ }^{9}$

Tabela 3. Localização do Polo do curso de graduação em Enfermagem na modalidade EaD nos estados segundo as regiões do Brasil, 2020.

\begin{tabular}{|c|c|c|c|c|c|c|c|}
\hline \multicolumn{8}{|c|}{ Localização do Polo EaD de Enfermagem } \\
\hline \multirow{2}{*}{ Regiões do país } & \multicolumn{2}{|c|}{ Capital } & \multicolumn{2}{|c|}{$\begin{array}{l}\text { Área metropolitana, }{ }^{1} \\
\text { excluído capital }\end{array}$} & \multicolumn{2}{|c|}{ Interior do estado } & \multirow[t]{2}{*}{$p$-valor ${ }^{2}$} \\
\hline & $\mathrm{N}$ & $\%$ & $\mathrm{~N}$ & $\%$ & $\mathrm{~N}$ & $\%$ & \\
\hline Nordeste & 61 & 17,3 & 63 & 17,8 & 229 & 64,9 & \\
\hline Norte & 40 & 17,9 & 27 & 12,1 & 156 & 70,0 & \\
\hline Centro-oeste & 43 & 28,1 & 18 & 11,8 & 92 & 60,1 & 0,001 \\
\hline Sudeste & 57 & 11,1 & 117 & 22,8 & 340 & 66,1 & \\
\hline Sul & 10 & 8,3 & 51 & 42,5 & 59 & 49,2 & \\
\hline Total & 211 & 15,5 & 276 & 20,2 & 876 & 64,3 & \\
\hline
\end{tabular}

Fonte: Portal e-MEC, 2020.9

Notas: 1- Municípios pertencentes às Regiões Metropolitanas (RM) ou em Regiões Integradas de Desenvolvimento (RIDE's) ou aos Aglomerados Urbanos (AU); 2- Teste de Qui-quadrado de Pearson. 


\section{DISCUSSÃO}

A pesquisa evidenciou aumento relevante da oferta de cursos de graduação em saúde na modalidade EaD no Brasil, corroborando com pesquisa realizada em 2018, a qual destacou que no período de 1993 a 2013 os cursos de graduação da saúde com ensino a distância já apresentavam uma expansão significativa no Brasil, sendo o setor privado responsável pela maior parte desse crescimento. ${ }^{13}$

Para a Enfermagem, observou-se elevado número de vagas ativas $(n=82.000)$ e essas poderiam ser cursadas em 1.363 Polos. Contudo, estudos prévios apontam que para Enfermagem haveria distorção entre o volume de vagas ofertadas e matrículas efetivadas, que se caracteriza pela ociosidade de quase $80 \%$ das vagas ofertadas na modalidade à distância. ${ }^{11,14}$ Parte dessa situação pode decorrer da heterogênea distribuição geográfica desses Polos dentro do país.

A Enfermagem foi uma das primeiras profissões a ofertar a graduação na modalidade EaD e a abertura de seus cursos ocorreu até 2016. ${ }^{10}$ Para as demais graduações da saúde, o aumento ocorreu posteriormente entre 2017 e 2020. Os motivos dessa diferença temporal na abertura de cursos de graduação entre a Enfermagem e as outras graduações em saúde podem decorrer de dois fatos.

O primeiro atribuído às rotinas legais de abertura e o segundo mais associado ao modelo de negócio. Em 2017, o Ministério da Educação (MEC) regulamentou o Decreto no 9.057/2017, ${ }^{15}$ por meio do qual se efetivou medidas que ampliaram ainda mais a oferta de cursos de ensino superior no país, flexibilizando a abertura de novos cursos para área de saúde na modalidade EaD. Já a ausência da criação de novos cursos EaD para educação superior em Enfermagem a partir de 2016 também pode decorrer da regulamentação instituída pelo Decreto no 9.237/2017. ${ }^{16}$ Esse deu ao Conselho Nacional de Saúde (CNS) a prerrogativa de avaliar e emitir parecer opinativo sobre os atos regulatórios de autorização e reconhecimento de cursos de graduação de Enfermagem junto ao Ministério da Educação. Além disso, o próprio CNS tem elaborado resoluções colocando-se formalmente contrário a oferta de cursos de graduação da área da saúde em EaD. ${ }^{11}$ Até então, a necessidade do parecer do CNS para regular a oferta de cursos se fazia necessária somente para Odontologia, Medicina, Psicologia e Direito. Tal exigência pode ter também contribuído para a ausência de cursos na modalidade EaD para estas graduações no banco de dados do e-MEC em todo período analisado neste estudo.

Em relação ao modelo de negócio, nos últimos anos também é possível observar estagnação do mercado de trabalho e dos salários para Enfermagem, ${ }^{17}$ que pode ter reduzido a busca desses cursos por novos candidatos. Assim, o mercado da educação superior parece ter realizado novos movimentos de acomodação a menor demanda, reconfigurando suas estratégias de mercado para diversificar sua oferta para outros cursos da área da saúde que tiveram suas regras de abertura flexibilizadas desde 2017.

Apesar dessa recente restrição, no início de 2020 existia um total de 274.792 vagas ativas para os cursos de graduação em Enfermagem (presencial e a distância), sendo quase 30\% delas na modalidade EaD. Essa condição torna a Educação em Enfermagem superior na modalidade EaD a quinta com maior número de vagas na área da saúde, atrás apenas dos cursos de Serviço Social, Fisioterapia, Nutrição e Biomedicina. ${ }^{9}$

A maior abertura econômica para o setor privado no mercado de educação superior foi iniciada com a flexibilização promovida pela Lei das Diretrizes e Bases da Educação Nacional em 1996. ${ }^{18}$ Essa induziu a atuação de grupos e corporações privadas que se organizaram na lógica de mercado para ofertar grande número de graduações. Com isso, houve maior crescimento dos cursos superiores de Enfermagem, entre eles aqueles na modalidade EaD. ${ }^{7}$ O número expressivo de 82.000 vagas autorizadas para graduação em Enfermagem em EaD, todas ofertadas por IES privadas, indica que esse desenvolvimento no Brasil vem sofrendo a influência das prerrogativas expansionistas do mercado educacional, anteriormente já observada para a graduação na modalidade presencial. ${ }^{19}$

No entanto, essa "mercantilização" da educação e expansão do ensino EaD, tem gerado importantes debates sobre a validade e qualidade do ensino superior privado no Brasil. ${ }^{7,20}$ Isso porque as profissões da saúde envolvem diversas situações práticas e a necessidade do desenvolvimento de competências gerais e específicas conforme as DCNs da Enfermagem, da interação técnica, social e afetiva com usuários e outros profissionais nos serviços de saúde. Esses elementos são de sobremaneira os mais prejudicados na modalidade de EaD.

A inclusão de parte dos conteúdos no formato EaD vem acontecendo de forma rápida também nos cursos presenciais de graduação. Em 06/12/2019 foi publicada a Portaria no 2.117 que autorizou as IES a ampliarem para até $40 \%$ a carga horária da EaD na organização pedagógica e curricular em todos os cursos de graduação presencial, exceto para o curso de graduação em Medicina. ${ }^{21}$ Entretanto, para o Cofen e Associação Brasileira de Enfermagem essa ampliação vai contra as DCNs de Enfermagem, pois fragiliza a formação da enfermeira (o) que deve ser de caráter essencialmente presencial. ${ }^{11}$

Apoiados nessa ideia, essas entidades lutam pela aprovação de projetos de lei que obriguem a formação exclusivamente em cursos presenciais para os profissionais de Enfermagem, argumentando que no formato $\mathrm{EaD}$ não é possível qualificar adequadamente em termos técnicos os profissionais, nem fazer com que estes lidem com as relações humanas, o que pode contribuir para perda da qualidade do cuidado, riscos à saúde e induzir assistência desumanizada e impessoal. ${ }^{11,22}$

Estudos internacionais até demonstram a importância da EaD como possibilidade de formação de recursos humanos da Enfermagem. ${ }^{23}$ Todavia, desafios colocados pela literatura também demonstram a preocupação com aquilo que é mais caro para a profissão: o desenvolvimento de competências clínicas e relacionais para o cuidado e atuação interprofissional. ${ }^{24,25}$

Destacou-se no estudo, relevante concentração de Polos EaD em cidades localizadas no interior dos estados (64,3\%), o que de fato possibilitou a implantação de cursos EaD para 
Enfermagem em áreas mais remotas e de difícil acesso, permitindo a democratização do ensino superior. Essa característica fortalece o principal argumento para existência desses cursos no país.

Por outro lado, os critérios definidos no Decreto no 9.235/2017, para visitas in loco das comissões de avaliação de curso, estabelecem que essas ocorram somente nas Sedes desses cursos, sem necessidade de visitas aos Polos, ${ }^{16}$ gerando importante preocupação. Isso porque, dada a capilarizacão desses 1.363 Polos ativos de EaD em Enfermagem no país, é possível que haja grande variabilidade na infraestrutura de laboratórios e da rede de serviços locais para as práticas e estágios, comprometendo de sobremaneira a qualidade da formação, principalmente nas áreas mais remotas do país, tendo em vista as fragilidades e variedades de concepções das práticas nessas áreas. ${ }^{11}$

Apesar da maior capilaridade dos Polos para o interior dos estados, ainda se verificou que há parte significante deles concentrados nas áreas metropolitanas ou capitais (35,7\%) e regiões mais ricas e centrais do país $(49,6 \%$ nas regiões Sul e Sudeste), sendo cerca de $1 / 4$ somente no estado de São Paulo. Essa heterogênea intensidade e distribuição dos Polos, faz com que o estado de São Paulo sozinho tenha quase a mesma proporção de Polos que as regiões Norte e Centro-Oeste juntas (24,5\%). Estudo realizado com dados do Instituto Nacional de Estudos e Pesquisas Educacionais (Inep) de 2017, destacou a expansão da modalidade EaD para Enfermagem na região Nordeste e Norte, ${ }^{25}$ no entanto, pode-se evidenciar com os dados do e-MEC a elevada concentração de Polos na região Sudeste.

Logo, parece haver particular movimento para criação e expansão dos Polos de ensino EaD na Enfermagem. Este se caracterizou por ocorrer em direção ao interior dos estados, mas concentrando-os nas regiões mais ricas e centrais do centrais do país. Essa condição também já foi observada para cursos presenciais, ${ }^{10,19}$ e pode ter seguido mais a lógica capitalista do mercado de educação do que a necessidade e demanda de saúde de cada região, apresentando relação direta com o desenvolvimento socioeconômico e tecnológico do país, já que os estados da região Sul e Sudeste são mais urbanizados e economicamente desenvolvidos. Essa sobreposição, perpetua o desequilíbrio regional da oferta desses profissionais, ${ }^{26,27}$ e induz formação acadêmica mais voltada para perfis epidemiológicos urbanos e distante da atenção qualificada que requerem áreas rurais e de floresta.

Outra possibilidade dessa concentração é que considerando esses contextos como complexos mais empregadores, faculdades privadas ampliaram a oferta de vagas para setores menos favorecidos da população e para profissionais que já possuíam profissionalização técnica em Enfermagem anterior a graduação. Essa expansão do ensino superior tem se apoiado no fenômeno da certificação para capilarizar o EaD nas regiões mais ricas do país e com melhores possibilidades de sustentabilidade e retorno.

Nesse cenário, embora tenha sido estabelecido na Constituição Federal a ordenação da formação de recursos humanos na área da saúde como atribuição ao Sistema Único de Saúde (SUS), há de se considerar que diante do intenso crescimento e da privatização dos cursos de graduação em Enfermagem na modalidade $\mathrm{EaD}$, tem prevalecido a lógica de mercado, o que tornou o setor da educação altamente rentável para as IES privadas. ${ }^{10}$ Essa condição espelha também a desconexão do setor educação com o de saúde e com as necessidades de saúde das populações das regiões menos desenvolvidas e socialmente mais vulneráveis.

Apesar desses resultados, convém destacar algumas limitações. $O$ banco de dados utilizado só permitiu verificar a data do ano de criação e não do início de funcionamento dos cursos. O portal e-MEC analisado na pesquisa não disponibiliza o número de concluintes por esses cursos. No site do Inep estão disponíveis esses dados, porém somente até 2018. Entre 2010 e 2018 foram 763 concluintes. ${ }^{7,10}$ Como existe a ausência dos dados de 2019 e $2020^{7,10}$ ainda não é possível identificar o volume total que a formação EaD já implicou na oferta de mão de obra. Também vale ressaltar a escassez de trabalhos que abordem a expansão da EaD para área da saúde e Enfermagem, dificultando o comparativo dos resultados aqui encontrados com outros estudos.

Apesar dessas limitações, acredita-se que os resultados aqui apresentados constituem fonte de informação e reflexão para diversos profissionais sobre repercussões que essa expansão da modalidade EaD traz a eles, a própria Enfermagem e ao campo da saúde, educação e mercado de trabalho.

\section{CONCLUSÃO E IMPLICAÇÕES PARA A PRÁTICA}

Os resultados indicaram aumento relevante da oferta de cursos de graduação em saúde na modalidade de EaD no Brasil. Para Enfermagem, sua expressiva expansão ocorreu em estágio anterior ao que vem acontecendo com os demais cursos de graduação da área da saúde. Essa expansão, caracterizouse por elevado o número de vagas, ofertadas por instituições privadas e localização dos seus Polos de ensino no interior de todos os estados do país. Contudo, a distribuição regional dessa oferta é desigual e ainda se sobrepõe à já observada para os cursos presenciais, mantendo a concentração de grande parte dos Polos nas regiões e estados mais ricos e centrais do país, e longe das áreas com maiores necessidades de saúde.

Logo, a rápida e crescente oferta de cursos EaD em Enfermagem traz principalmente a preocupação sobre a qualidade desses cursos. Ao mesmo tempo em que essa formação ainda se concentra em grandes centros, ela pode não considerar a diversidade das condições e necessidades de saúde da população e as várias características organizativas do sistema de saúde do Brasil.

\section{FINANCIAMENTO}

O presente trabalho foi realizado com apoio da Coordenação de Aperfeiçoamento de Pessoal de Nível Superior - Brasil (CAPES), Código de Financiamento 001, ao Programa de Pós-graduação em Enfermagem da UFMA. Mas, sem concessão de bolsa. 


\section{CONTRIBUIÇÕES DOS AUTORES}

Concepção do desenho do estudo. Fabiana Alves Soares. Coleta de dados. Fabiana Alves Soares.

Análise de dados. Fabiana Alves Soares. Bruno Luciano Carneiro Alves de Oliveira. Raquel de Aguiar Portela. Karla Kelma Almeida Rocha. Andréa Cristina Oliveira Silva. Rita da Graça Carvalhal Frazão Corrêa.

Interpretação dos dados. Fabiana Alves Soares. Bruno Luciano Carneiro Alves de Oliveira Redação e revisão crítica do artigo: Fabiana Alves Soares. Bruno Luciano Carneiro Alves de Oliveira. Raquel de Aguiar Portela. Andréa Cristina Oliveira Silva. Rita da Graça Carvalhal Frazão Corrêa. Karla Kelma Almeida Rocha.

Aprovação da versão final do artigo. Fabiana Alves Soares. Karla Kelma Almeida Rocha. Raquel de Aguiar Portela. Andréa Cristina Oliveira Silva. Rita da Graça Carvalhal Frazão Corrêa. Bruno Luciano Carneiro Alves de Oliveira.

Responsabilidade por todos os aspectos do conteúdo e a integridade do artigo publicado. Fabiana Alves Soares. Karla Kelma Almeida Rocha. Raquel de Aguiar Portela. Andréa Cristina Oliveira Silva. Rita da Graça Carvalhal Frazão Corrêa. Bruno Luciano Carneiro Alves de Oliveira,

\section{EDITOR ASSOCIADO}

Rafael Celestino da Silva

\section{REFERÊNCIAS}

1. Cruz JR, Lima DCP. Trajetória da educação a distância no Brasil: políticas, programas e ações nos últimos 40 anos. Jornal de Políticas Educacionais. 2019 abr 24;13(13):1-19. http://dx.doi.org/10.5380/jpe. v13i0.64564.

2. Barros, ASX. Expansão da educação superior no Brasil: limites e possibilidades. Educ Soc. 2015 abr/jun;36(131):361-90. http://dx.doi. org/10.1590/ES0101-7330201596208.

3. Fialho $\mathrm{SH}$, Barros MJH, Rangel MTR. Desafios da regulação da EAD no ensino superior no brasil: estrutura, Diálogo e Autonomia Institucional. Revista Gestão e Planejamento. 2019 jan/dez;20:110-25. http://dx.doi. org/10.21714/2178-8030gep.v.20.5706.

4. França Fo AL, Antunes CF, Couto MAC. Alguns apontamentos para uma crítica da EAD na educação brasileira em tempos de pandemia. Revista Tamoios. 2020 jan/jun;16(2):16-31. http://dx.doi.org/10.12957/ tamoios.2020.50535.

5. Lei n. 9349 de 20 de dezembro de 1996 (BR). Dispõe sobre as diretrizes e bases da educação nacional no Brasil. Diário Oficial da União [periódico na internet], Brasília (DF), 21 dez. 1996 [citado 20 jul 2019]. Disponível em: http://www.planalto.gov.br/ccivil_03/leis/19394.htm

6. Decreto № 5.622 de 19 de dezembro de 2005 (BR). Regulamenta o art. 80 da Lei no 9.394, de 20 de dezembro de 1996, que estabelece as diretrizes e bases da educação nacional. Diário Oficial da União [periódico na internet], Brasília (DF), 20 dez. 2005 [citado 21 jun 2019]. Disponivel em: http://portal.mec.gov.br/sesu/arquivos/pdf/portarias/ dec5.622.pdf

7. Instituto Nacional de Estudos e Pesquisas Educacionais Anísio Teixeira. Censo da Educação Superior 2018: notas estatísticas. Brasília: INEP; 2019 [citado 20 jun 2018]. Disponível em: http://download.inep.gov.br/ educacao_superior/censo_superior/documentos/2019/censo_da_edu cacao_superior_2018-notas_estatisticas.pdf

8. Tanaka EZ, Sartori DVB, Ferreira LR, Bermejo LJ. A educação a distância nos cursos de graduação em enfermagem: aplicação e efetividade. Revista on line de Política e Gestão Educacional. 2017 jun;21(1):83141. http://dx.doi.org/10.22633/rpge.v21.n.esp1.out.2017.10455.
9. Ministério da Educação (BR). Sistema e-MEC [Internet]. Brasília: Ministério da Educação; 2020 [citado 11 fev 2020]. Disponível em: http://portal.inep.gov.br/

10. Moyses NMN, Vieira AS. Graduation trajectory of the fourteen health professions in Brasil. Saúde debate. 2017 abr/jun;41(113):401-14. http://dx.doi.org/10.1590/0103-1104201711305.

11. Humerez CD, Silva MCN, OhI RIB, Jankevinicius JV, Dias OV, Borges RF. Normativas regulatórias dos cursos de enfermagem a distância: ações e reações do Conselho Federal de Enfermagem. Rev. Enferm Foco. 2019;10(2):142-8. http://dx.doi.org/10.21675/2357-707X.2019. v10.n2.2338.

12. Pepin JI, Myrick F. Quality nursing education in unprecedented times -teaching and learning for the unexpected. QUANE/AFI. 2020;6(1):1-3. https://doi.org/10.17483/2368-6669.1242.

13. Franco AVF, Poz MRD. A participação de instituições de ensino superior privadas na formação em saúde no Brasil. Trab Educ Saúde. 2018;16(3):1017-37. http://dx.doi.org/10.1590/1981-7746-sol00163.

14. Sanes MDS, Neves FBD, Pereira LEM, Ramos FRS, Brehmer LCF, Vargas MAO et al. No to distance education! Production of meaning of discourses of nursing representative entities. Rev Bras Enferm. 2020;73(5):e20190465. http://dx.doi.org/10.1590/0034-7167-20190465. PMid:32667401.

15. Decreto n. 9.057 de 25 de março de 2017 (BR). Dispõe sobre a oferta de cursos na modalidade a distância. Diário Oficial da União [periódico na internet], Brasília (DF), 25 mar 2015 [citado 10 jun 2019]. Disponíve em: http://www.planalto.gov.br/ccivil_03/_ato2015-2018/2017/decreto/ d9057.htm

16. Decreto n. 9.235 de 15 de dezembro de 2017 (BR). Dispõe sobre o exercício das funções de regulação, supervisão e avaliação das instituições de educação superior e dos cursos superiores de graduação e de pós-graduação no sistema federal de ensino. Diário Oficial da União [periódico na internet], Brasília (DF), 15 dez 2017 [citado 10 ago 2019]. Disponível em: http://www.planalto.gov.br/ccivil_03/_Ato20152018/2017/Decreto/D9235.htm

17. Machado MM, Oliveira E, Lemos W, Lacerda WF, Aguiar Fo W, Wermelinger $M$ et al. Mercado de trabalho da Enfermagem: aspectos gerais. Enferm Foco. [Internet]. 2015; [citado 10 ago 2019];6(1/4):43-78. Disponível em: http://biblioteca.cofen.gov.br/wp-content/uploads/2016/07/Mercadode-trabalho-da-enfermagem-aspectos-gerais.pdf

18. Campista TMN, Baptista SS, Coelho MCR, Almeida Fo AJ, Xavier ML Panorama do campo da educação superior em enfermagem no estado do Espírito Santo. Esc Anna Nery Rev Enferm. 2009 abr/jun;13(2):25664. http://dx.doi.org/10.1590/S1414-81452009000200004.

19. Frota MA, Wermelinger MCMW, Vieira LJES, Ximenes No FRG, Queiroz RSM, Amorim RF. Mapeamento a formação do enfermeiro no Brasil: desafios para atuação em cenário complexos e globalizados. Cien Saude Colet. 2020;25(1):25-35. http://dx.doi.org/10.1590/141381232020251.27672019. PMid:31859852.

20. Santos AC. Educação Superior a Distância no Brasil: democratização da oferta ou expansão do mercado. RBPAE. 2018;34(1):167-88. http:// dx.doi.org/10.21573/vol34n12018.82470.

21. Portaria n. 2.117 de 6 de dezembro de 2019 (BR). Dispõe sobre a oferta de carga horária na modalidade de Ensino a Distância - EaD em cursos de graduação presenciais ofertados por Instituições de Educação Superior - IES pertencentes ao Sistema Federal de Ensino. Diário Oficial da União [periódico na internet], Brasília (DF), 7 dez 2019 [citado 10 jan 2020]. Disponível em: http://www.in.gov.br/en/web/dou/-/ portaria-n-2.117-de-6-de-dezembro-de-2019-232670913

22. Projeto de Lei n. 2.891 de 2015 (BR). Altera a Lei no 7.498 , de 25 de junho de 1986, que regulamenta o exercício da enfermagem, para nela incluir a obrigatoriedade de formação exclusivamente em cursos presenciais para os profissionais da área [periódico na internet], Brasília (DF), 26 jun 2015 [citado 20 jun 2020]. Disponível em: https://www.camara.leg. $\mathrm{br} /$ proposicoesWeb/fichadetramitacao?idProposicao $=1712329$

23. Najafi Ghezeljeh T, Mohammad Aliha J, Haghani H, Javadi N. Effect of education using the virtual social network on the knowledge and attitude of emergency nurses of disaster preparedness: a quase experiment study. Nurse Educ Today. 2019;73:88-93. http://dx.doi.org/10.1016/j. nedt.2018.12.001. PMid:30550943. 


\section{Educação a distância em saúde no Brasil}

Soares FA, Rocha KKA, Portela RA, Silva ACO, Corrêa RGCF, Oliveira BLCA

24. McDonald EW, Boulton JL, Davis JL. E-learning and nursing assessment skills and knowledge: an integrative review. Nurse Educ Today.2018;66:16674. http://dx.doi.org/10.1016/j.nedt.2018.03.011. PMid:29705504.

25. Letícia KM, Rosa MR, Raphael KS, Solange FRC, Mateus SL. Expansão dos cursos de enfermagem no Brasil entre 2004 e 2017. Enferm. Foco. 2019;10(6):63-9. http://dx.doi.org/10.21675/2357-707X.2019.v10. n6.2369.
26. Marinho GL, Paz EPA, Jomar RT, Abreu AMM. Enfermeiros no Brasil: transformações socioeconômicas no início do século XXI. Esc Anna Nery. 2019 jan 24;23(1). http://dx.doi.org/10.1590/2177-9465-ean-2018-0198.

27. Matsumura ESS, França AS, Alves LMF, Da Silveira MKS, Sousa Jr ADS, Cunha KD. Distribuição espacial dos cursos de graduação em enfermagem. Rev. Enferm. UFPE. 2018 dez;12(12):3271-8. http://dx.doi org/10.5205/1981-8963-v12i12a236270p3271-3278-2018.

a Artigo extraído da produção acadêmica em desenvolvimento, com o título: Expansão e distribuição do ensino superior em Enfermagem no Brasil, de autoria
de Fabiana Alves Soares, orientada por Bruno Luciano Carneiro Alves de Oliveira. Programa de Pós-Graduação em Enfermagem da Universidade Federa do Maranhão. 